\title{
Microbial Agents Causing Infective Corneal Ulcer and their Anti-microbial Susceptibility pattern
}

\author{
*Jhuma $\mathrm{AA}^{1}$, Haque $\mathrm{MM}^{2}$, Ahmed J3 , Das $\mathrm{S}^{4}$, Paul TK$K^{5}$, Rahman $\mathrm{MM}^{6}$
}

\begin{abstract}
This study was designed to identify the microbial agents causing infective corneal ulcer and to carry out the antimicrobial susceptibility patterns of isolated bacteria causing infective corneal ulcer. Out of 80 samples, 67 (83.75\%) cases were positive by microscopy and culture. This study showed pure fungal growth in 39 (48.75\%) cases, pure bacterial growth in 8 (10\%) cases, mixed microbial growth (both fungi and bacteria) in 20 (25\%) cases and no growth was observed in 13 (16.25\%) cases. Among the fungal isolates, Aspergillus species was the leading agent detected in 37(46.3\%) cases followed by Penicillium species in 7 (8.8\%) instances. Pseudomonas aeruginosa was the most common bacterial pathogen found in 11 (13.8\%) cases followed by Staphylococcus epidermidis present in 9 (11.3\%) cases. Gentamicin, Ciprofloxacin and Levofloxacin were found to be better efficacious drugs against most of the bacterial pathogens noted in antimicrobial susceptibility test. This study showed that infective corneal ulcers are caused by both bacterial and fungal agents but fungal agents are more common. The findings of this study would help the ophthalmologists in evidence based management of their patients of infective corneal ulcer.
\end{abstract}

Keywords: Infective corneal ulcer, antimicrobial susceptibility patterns, aspergillus species, pseudomonas aeruginosa

1. *Dr. Azima Aktar Jhuma, Lecturer, Department of Microbiology, Sylhet MAG Osmani Medical College, Sylhet. Email; jhumaaktar.aa@gmail.com

2. Dr. Md. Moynul Haque, Professor \& Head of the Department of Microbiology, Sylhet MAG Osmani Medical College, Sylhet.

3. Dr. Jamil Ahmed, Professor of Ophthalmology, Parkview Medical College, Sylhet.

4. Dr. Shantanu Das, Lecturer, Department of Microbiology, Sylhet MAG Osmani Medical College, Sylhet.

5. Dr. Tarun Kanti Paul, Lecturer, Department of Microbiology, Sylhet MAG Osmani Medical College. Sylhet.

6. Dr. Md. Mahbubur Rahman, Assistant Professor, Department of Microbiology, Central Medical College, Cumilla.

*For correspondence

\section{INTRODUCTION}

Corneal ulcer is a serious sight threatening disorder presenting in all age and sex worldwide. It can lead to irreversible damage of the cornea in short time and consequently cause monocular blindness. ${ }^{1}$ Every year about 1.5 to 2 million new cases of blindness are caused by corneal diseases in which ocular trauma and corneal ulceration are the main causes. $^{2}$

A wide spectrum of microbial agents can produce corneal ulcer including bacteria, fungi, virus and parasites. Of them, bacteria and fungi are more common in developing countries. ${ }^{3}$ The most common bacteria causing corneal ulceration are Streptococcus, Pseudomonas, Enterobacteriaceae and Staphylococcus species. ${ }^{4,5}$ Aspergillus (40-60\%) and Fusarium (30-50\%) are leading fungal agents causing corneal ulcer followed by Penicillium (5-15\%) species. ${ }^{6}$ Other fungi like Candida, Mucor, Rhizopus and Curvularia are also responsible for corneal ulcer ${ }^{7}$.Fungal corneal ulcer is an important cause of vision loss in tropical and developing countries. ${ }^{8}$ About $20 \%$ cases of fungal ulcers are complicated by bacterial co-infection. ${ }^{?}$

The consequences of untreated or severely infected corneal ulcer are opacification and perforation of cornea, endophthalmitis and ultimately impairment of vision. Corneal destruction may be complete in 24-48 hours with some strains of virulent bacterial agents like S.aureus, S.pneumoniae, N.meningitidis, H.influenzae and Ps.aeruginosa. ${ }^{10}$ Most of these cases are due to lack of diagnostic facilities and appropriate treatment. Prompt and accurate identification of the causative microorganisms and selection of appropriate antibiotics is the key of specific treatment. $^{8}$ Microbial cause of corneal ulcer varies significantly between countries, even from region to region within the same country as it varies with patient population, geographical location and climate. ${ }^{11}$ The sensitivity pattern of antibiotics also varies from region to region. ${ }^{12}$ So, the therapeutic strategies are also variable.

In Bangladesh about 39-55\% of all cases of unilateral blindness were caused due to complication of corneal 
ulcer. ${ }^{13}$ Several studies on corneal ulcer were carried out at different countries. Some studies showed that bacterial corneal ulcer is more common. ${ }^{12,14}$ But most studies showed fungus is the common cause of corneal ulcer in developing countries like us and the incidence is increasing rapidly. ${ }^{13,15-17}$ This increased incidence is due to growing number of trauma cases, wide spread abuse of broad spectrum antibiotics and steroids. ${ }^{18}$ The injudicious and empirical use of cortisone and its derivatives combined with antibiotics, suppressing the immune response, favors the growth of fungi and also cause invasive type of infection. ${ }^{13}$

Bacterial corneal ulcer often causes devastating condition by its rapid spread, potential complication and poor prognosis. Recent reports suggested that bacterial resistance to antibiotic agents is becoming increasing in ocular infection. ${ }^{10,14,19}$ So, bacteria isolated from corneal ulcer must be periodically reviewed against available antibiotics to know the susceptibility pattern. By this way, misuse of antibiotic with its consequent effect will be minimized and the period of treatment will also be shortened.

\section{MATERIALS AND METHODS}

This cross-sectional study was carried out in the department of Microbiology in collaboration with the department of Ophthalmology, Sylhet MAG Osmani Medical College Hospital from $1^{\text {st }}$ July 2015 to $30^{\text {th }}$ June 2016. All clinically diagnosed patients of infective corneal ulcer were included in this study. Systemic disease associated ulcer, viral corneal ulcer and non-healing ulcer like mooren ulcer, marginal ulcer, interstitial keratitis \& neurotrophic ulcer were excluded. After explaining the purpose of the study, informed written consent was taken from each patient or legal guardian. Prior to the beginning of this study, approval of the research protocol was obtained from the Ethical Review Committee of Sylhet MAG Osmani Medical College, Sylhet.

Samples were collected by the ophthalmologist with all aseptic precautions. One corneal swab and three corneal scrapings were collected from each patient. Corneal swab was taken for isolation of bacteria from the ulcerated area of the cornea with sterile cotton swab soaked with sterile normal saline. Blood agar media and MacConkey's agar media were used for culture of bacteria. Specific organisms were isolated and identified by standard laboratory procedure based on colony morphology, microscopic features, staining characteristics and biochemical properties. Antimicrobial susceptibility pattern were determined by Kirby-Bauer modified disk-diffusion method on Mueller-Hinton agar plates as per Central Laboratory Standard Institute (CLSI) guidelines. After taking corneal swab, two drops of preservative free local anesthetic ( $0.4 \%$ oxybuprocaine) was given to the eye. Five minutes after instillation of local anesthetic, three corneal scrapings were taken by using Bard-Parker blade (No.15) under microscope. First scraping material was used for $10 \%$ potassium hydroxide $(\mathrm{KOH})$ wet mount. Fungus was cultured on Saboraud's Dextrose Agar (SDA) media with Chloramphenicol from second scraping material and last scraping material was used for gram staining. Inoculated SDA media was incubated at $25^{\circ} \mathrm{C}$ and observed daily for first 7 days and on alternate days for the next 7 days for observing slow growing fungi. Identification of fungal growth was done by its macroscopic and microscopic features.

\section{RESULTS}

Total 80 patients of infective corneal ulcer were selected according to inclusion and exclusion criteria. Out of 80 cases, culture was found positive in $67(83.75 \%)$ cases. Pure fungal growth was isolated in $39(48.75 \%)$ cases, pure bacterial growth in $8(10 \%)$ cases, mixed microbial growth (both fungus and bacteria) in 20 (25\%) cases and no growth was found in $13(16.25 \%)$ cases.

\section{Table I: Showing isolated microorganisms from culture of corneal ulcer patients. $(\mathrm{N}=80)$}

\begin{tabular}{|l|c|c|}
\hline Isolated microorganism & Frequency (n) & Percentage (\%) \\
\hline Fungus & 39 & 48.75 \\
\hline Bacteria & 08 & 10.00 \\
\hline $\begin{array}{l}\text { Mixed (both fungus and } \\
\text { bacteria) }\end{array}$ & 20 & 25.00 \\
\hline No organism & 13 & 16.25 \\
\hline Total & 80 & 100 \\
\hline
\end{tabular}

Out of total 59 (both pure fungus and mixed growth) fungal isolates, Aspergillus species 37(46.3\%) were the commonest fungus. Among Aspergillus, Aspergillus niger $16(20 \%)$ were the highest in number. Then Aspergillus flavus 8 (10\%), Aspergillus fumigatus 7 (8.8\%) and Aspergillus terreus $6(7.5 \%)$ in order of their frequency. Other isolated fungi were Penicillium species 7 (8.8\%), Fusarium species 6 (7.5\%), Mucor 6 (7.5\%) and Rhizopus $2(2.5 \%)$. The following bar diagram showing the fact- 


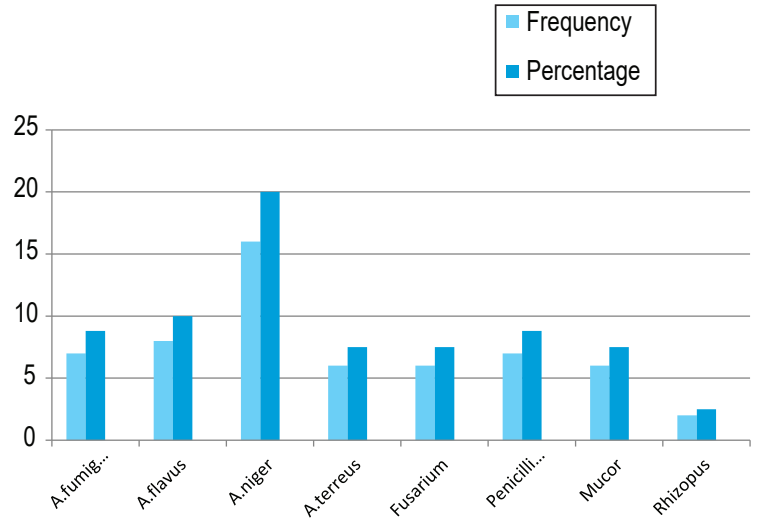

Figure 1: Bar diagram showing different fungal species isolated from corneal ulcer patients.

Out of 28 bacterial strain (including mixed with fungus) isolated from corneal ulcer patients, Pseudomonas aeruginosa was the most common isolates representing 11 (13.8\%) cases. The next common isolated bacteria were Staphylococcus epidermidis present in 9 cases (11.3\%). The other isolates were in order of frequency Staphylococcus aureus in $3(3.8 \%)$ cases, Klebsiella species in $3(3.8 \%)$ cases and Escherichia coli in 2 (2.5\%) cases.

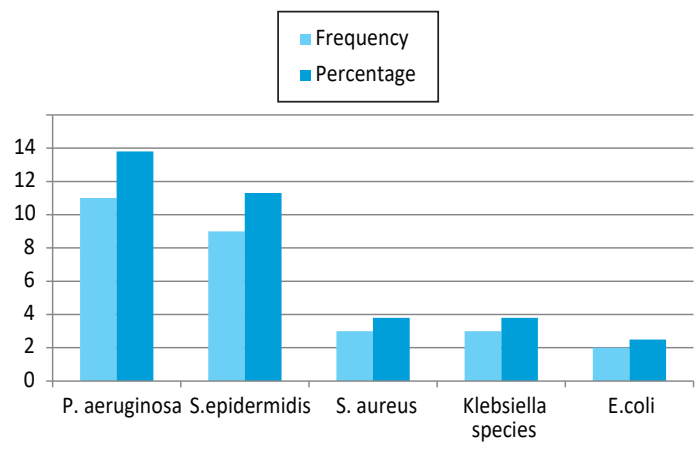

Figure 2: Bar diagram showing distribution of bacterial species among culture positive cases.

AST was done against the 28 isolated bacteria from the samples. All the isolates were $100 \%$ sensitive to gentamicin and highly sensitive to ciprofloxacin (82.1\%) and levofloxacin $(71.4 \%)$. All the bacterial isolates showed resistance to ceftazidime (100\%). The isolates were also found highly resistant to cefuroxime (92.9\%), erythromycin (92.9\%), chloramphenicol (82.1\%) and vancomycin $(82.1 \%)$.

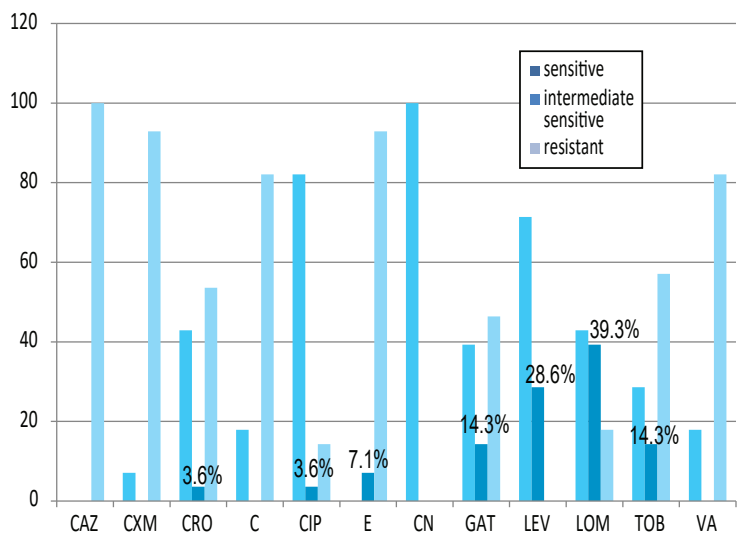

$\mathrm{CAZ}=$ Ceftazidime, $\mathrm{CXM}=$ Cefuroxime, $\mathrm{CRO}=$ Ceftriaxone, $\mathrm{C}=$ Chloramphenicol, $\mathrm{CIP}=$ Ciprofloxacin, $\mathrm{E}=$ Erythromycin, $\mathrm{CN}=$ Gentamycin, GAT=Gatifloxacin, $\mathrm{LEV}=$ Levofloxacin, LOM=Lomefloxacin, TOB=Tobramycin, VA= Vancomycin.

Figure 3: Bar diagram showing antimicrobial susceptibility pattern of isolated microorganism from patients of infective corneal ulcer

\section{DISCUSSION}

In this study, among 80 samples, culture positive case was $67(83.75 \%)$. Total microbial etiology of $83.75 \%$ compared well with others. ${ }^{10,13,19}$ Among culture positive cases, pure fungal growth was detected in 39 (48.75\%) cases, pure bacterial growth in $8(10 \%)$ cases, mixed microbial growth (both fungus and bacteria) in 20 (25\%) cases and no growth was found in $13(16.25 \%)$ cases. This finding suggested that fungal agents were more common in causing infective corneal ulcer in this region.

Several studies regarding infective corneal ulcer were done in different regions of different countries where a wide variation in microbial agents causing infective corneal ulcer was observed. In India, 38.6\% pure fungus, $23.9 \%$ was pure bacteria and 5.5\% was mixed growth of bacteria and fungus were isolated from 800 studied group of corneal ulcer $^{20}$. In Thailand, $60 \%$ was bacteria and $40 \%$ was fungi were isolated in $2004^{21}$. In Oman, $88.26 \%$ bacteria and $11.84 \%$ fungi were isolated from 188 patients of corneal ulcer. ${ }^{12}$ Dunlop et al. (1994) isolated $53.5 \%$ bacterial and $35.9 \%$ fungal agents in a study conducted in Chittagong Eye Infirmary Bangladesh. ${ }^{22}$ Bacteria 42\%, fungus 08\% and mixed 04\% cases were observed in Sylhet MAG Osmani Medical College hospital, Sylhet in $1992{ }^{23}$ Akter. et al (2009) showed $42.86 \%$ fungal growth, $25 \%$ bacterial 
growth and 16.07\% mixed microbial growth (both bacteria and fungi) in Rajshahi Medical College Hospital, Bangladesh. ${ }^{13}$ Another study was done by Ahmed et al. in 2010 in Bangabandhu Sheikh Mujib Medical University and Islamia Eye Hospital, Dhaka. They isolated 32.8\% fungal, 20.8\% bacterial and 5.2\% mixed growth from 250 patients of corneal ulcer. ${ }^{17}$

In our study, fungi were identified as principle etiological agents of infective corneal ulcer. Fungi were isolated from a total $59(73.75 \%)$ cases of which pure fungal growth were in $39(48.75 \%)$ cases and mixed growth with bacteria in 20 $(25 \%)$ cases. It was consistent with the findings of researchers from different parts of the world. ${ }^{20}, 24$ Aspergillus spp. 37(46.3\%) was the commonest fungus. Other isolated fungi were Penicillium species 7 (8.8\%), Fusarium species 6 (7.5\%), Mucor 6 (7.5\%) and Rhizopus $2(2.5 \%)$. The fungal species detected in the present study was equally comparable with that of others. ${ }^{2,15}$ Aspergillus spp. was the most predominant fungal pathogen in Bangladesh, Eastern India, Egypt and Uttarakhand, India. 2,3,13,15,17. Aspergillus spp. is ubiquitious fungi commonly occurring in soil, water and decaying vegetation. ${ }^{6}$ This mould produces abundant small conidia that are easily aerosolized. ${ }^{25}$ The higher incidence of corneal infections by Aspergillus spp. is seen in drier climates which may be due to the fact that spores of Aspergillus can tolerate hot, dry weather conditions like us. ${ }^{26}$ We isolated $8.8 \%$ Penicillium spp. while Chhangte et al. (2015) isolated $6.1 \%$ in Uttarakhand, India. Fusarium spp. was found only in 6 $(7.5 \%)$ cases in our study but it was found the common fungal pathogen in Ghana (42.2\%), Northern India (38.46\%) and South India (45.85\%). ${ }^{8,16,20}$ This phenomenon may be explained by differences in climate and the natural environment of individual regions. Furthermore, nowaday, indiscriminate use of broad spectrum antibiotics, immunosuppressive drugs and corticosteroids enhance the rapid growth of fungi by suppressing immune response and decreasing local resistance of cornea.

In our study, bacteria were identified as etiological agents in $35 \%$ (10\% pure bacterial and $25 \%$ mixed with fungus) cases of corneal ulcer. It was consistent with the findings of other researchers. ${ }^{11,16,-24}$ When compared to the number of fungal isolates, less bacterial pathogens were detected in the present study. This result can be correlated with the fact that $33.8 \%$ patients enrolled in this study have treated with antibiotics or steroids before samples were collected and as a consequence fewer bacteria were isolated. Of the bacterial isolates, Pseudomonas spp. was the most common representing in $11(13.8 \%)$ cases. This finding is similar with other studies done in Bangladesh, Iran, Thailand, Oman and Hong Kong. ${ }^{12,14,21,22,} 27,28$ Again, this was different from other studies conducted in Bangladesh, Egypt, Eastern India, Northern India, South India and Switzerland. 3, 8, 13,-20, 23, 24 In our study, the next common isolated bacteria were Staphylococcus epidermidis present in 9 cases (11.3\%). But Staphylococcus epidermidis was isolated in $21.9 \%$ and $20 \%$ cases in Iran and Oman respectively $12,28$. We isolated Staphylococcus aerues in $3(3.8 \%)$ cases, Klebsiella spp. in $3(3.8 \%)$ cases and Escherichia coli in $2(2.5 \%)$ cases which was different from the study done by Tewari et al. (2012). They found 32.7\% Staphylococcus aureus, 6.8\% Klebsiella spp. and 5.1\% Escherichia coli in Ahmedabad, India. These might be due to variation in the principle causative microbial agents of infective corneal ulcer in different countries.

AST was done against all the isolated bacteria from the 28 cases. We found that all those isolates were highly sensitive to gentamicin (100\%), ciprofloxacin $(82.1 \%)$ and levofloxacin (71.4\%). All the bacterial isolates were resistant to cefotaxime (100\%). The isolates were also found highly resistant to cefuroxime (92.9\%), erythromycin $(92.9 \%)$, chloramphenicol $(82.1 \%)$ and vancomycin $(82.1 \%)$. Chloramphenicol, the frequently used ophthalmic antibiotic was found less effective against most of bacterial isolates. This was also reported by Akter et al. (2009) and Mahran et al. (2014).3,13 This poor performance of chloramphenicol may be due to its inappropriate and over use seen in common practice leading to drug resistance. Gentamicin, ciprofloxacin, and levofloxacin were found to be better efficacious drugs against most of the bacterial pathogens noted in in-vitro susceptibility testing.

\section{CONCLUSIONS}

Infective corneal ulcer is a common eye problem and is one of the major preventable causes of blindness in Bangladesh. It is caused by both bacterial and fungal agents but fungal agents are more common than bacteria in this geographical region. Resistance against common ocular antibiotics become increasing rapidly, so it is advisable to perform AST and modify the treatment according to the results of the sensitivity test. 


\section{REFERENCES}

1. Bastola P, Mishra A, Chaudhary N, Nath HK, Mehrotra AN. Spectrum of mycotic corneal ulcers in mid western peripheral region of terrain belt of Nepal and Indo-Nepal border. Nepal J Med. Sciences 2013; 02: 42-7.

2. Chhangte L, Pandey S, Umesh. Epidemiological and microbiological profile of infectious corneal ulcers in tertiary care centre, Kumaon Region, Uttarakhand. Int. J Scientific and Research Publications, 2015; 05: $1-5$.

3. Mahran M, Mohssen M, Negm S, Shafikk M. Multivariate Analysis of Microbial Keratitis in Egypt. World Appl. Sci. J. 2014; 32 (12): 2421-30.

4. Kanski J J, Bowling B. Cornea In: Clinical ophthalmology a systematic approach, 7 th $\mathrm{ed}$. China: Elsevier, Inc.; 2011: pp 168-96.

5. Sihota R, Tandon R. Diseases of the cornea In: Parsons's diseases of the eye, $21^{\text {st }}$ ed. New Delhi: Elsevier publishers 2011; pp 188-207.

6. Saleh AA. Fungal infections of the eye. In: Human Mycology. Dhaka: 2009; pp 72-4.

7. Chander J. Oculomycosis In: Textbook of Medical Mycology, $3^{\text {rd }}$ ed. New Delhi: Mehta publishers; 2008:

8. Ojha S, Tandon A, Shukla D, Saraswat N, Joshi S. Etiology of suppurative corneal ulcers in rural population of northern India. Ind. J of clinical and experimental ophthalmol. 2015; 01: 62-7.

9. Lopez FHM, 2014. Bacterial Keratitis (Last updated: Aug 28, 2014). Web page at: http://emedicine. medscape.com/article/ 1194028 -overview\#a 5 [Accessed on 20 February, 2016].

10. Kaliamurthi J, Kalavathy CM, Parmar P, Jesudasan CAN, Thomas PA. Spectrum of bacterial keratitis at a tertiary eye care centre in India. Bio Med Research Int. 2013; 1-8.

11. Patel S, Chaudhari AM, Solu TM, Gharat V. Epidemiological and microbiological profile of patient's having microbial keratitis. Natl J Community Med 2014: 05; 463-7.

12. Keshav BR, Zacheria G, Ideculla T, Bhat V, Joseph M. Epidemiological characteristics of corneal ulcers in south Sharqiya region. Oman Med J 2008; 23: 34-9.
13. Akter L, Salam MA, Hassan B, Begum N, Ahmed I. Etiological agents of suppurative corneal ulcer: study of 56 cases. Bangladesh J Med Microbiol 2009; 03: 33-6.

14. Lai THT, Jhanji V, Yong AL. Microbial keratitis profile at a university hospital in Hong Kong. Int. Scholarly Research Notices 2014; 1-4.

15. Basak SK, Basak S, Mohanto A, Bhowmick A. Epidemiological and microbiological diagnosis of suppurative keratitis in Gangetic West Bengal, Eastern India. Ind J Ophthalmol 2005, 53. 17-22.

16. Bharati MJ, Ramakrisna R, Vasu S, Meenakshi, Palaniappan R. Aetiological Diagnosis of microbial keratitis in south India. Ind J Med Microbiol 2002; 20: 19-24.

17. Ahmed S, Ghosh A, Hassan SA, Tarafder S, Miah MRA. Predisposing factors and etiologic diagnosis of infectious corneal ulcer. Bangladesh J Med Microbiol 2010; 04: 28-31.

18. Balagurunathan R, Shanthi J, Vanaja PR. Laboratory diagnosis and prevalence study of corneal infections from a tertiary eye care hospital. Advances in Appl Sci Research 2012; 03: 1598-1602.

19. Schaefer F, Bruttin O, Zografos L, Guex-Crosier Y. Bacterial Keratitis: a prospective clinical and microbiological study. Br J Ophthalmol 2001; 85: 842-7.

20. Leck AK, Thomas PA, Hagan M, Kaliamurthy J, Ackuaku E, John M. Etiology of suppurative corneal ulcers in Ghana and South India, and epidemiology of fungal keratitis. Br J Ophthalmol 2002; 86: 1211-5.

21. Tananuvat, N., S. Sienglew and S. Ausayakhun. 2004. Assoc. Thai, 85: 217-30.

22. Dunlop AA, Wright ED, Howlader SA, Nazrul I, Husain R, McClellan K, Billson FA. Suppurative corneal ulceration in Bangladesh. A study of 142 cases examining the microbiological diagnosis, clinical and epidemiological features of bacterial and fungal keratitis. Aust N Z J Ophthalmol. 1994; 22: 105-10.

23. Arif MM, Chowdhury OA, Kibria G. Clinicoetiological diagnosis of corneal ulcer.Trans. Ophthal. Soc. Bang 1992; 19: 31-7. 
24. Srinivasan M, Gonzales CA, George C, Cevallus v, Mascarenhas JM, Asokan B, et al. Epidemiology and aetiological diagnosis of corneal ulceration in Madurai, South India. Br. J Ophthalmol. 1997; 81: $965-71$.

25. Mitchel TG. Mycology In: Brooks GF, Carroll KC, Butel JS, Morse SA, Mietzner TA ed. Jawetz, Melnick $\&$ Adelberg's Medical Microbiology. $25^{\text {th }}$ ed. USA: McGraw-Hill Education; 2010: pp 651.

26. Khairallah SH, Byrne KA, Tabbara KF. Fungal keratitis in Saudi Arabia. Doc Ophthalmol 1992; 79: 269-76.
27. Williams G, Billson F, Husain R, Howlader SA, Islam N, Mcclellan K. Microbiological diagnosis of suppurative keratitis in Bangladesh. Br J Ophthalmol 1987; 71: 315-21.

28. Shoja MR, Manaviat M. Epidemiology and outcome of corneal ulcers in Yazd Shahid Sadoughi Hospital. Acta Medica Iranica 2004; 42: 136-41.

29. Tewari A, Sood N, Vegad MM, Mehta DC. Epidemiological and microbiological profile of infective keratitis in Ahmedabad. Ind J Ophthalmol 2012; 60: 268-72. 